of his treatment of the subject was that it is the power to form propositions that is affected, and not the memory of words or faculty of language; the higher the propositional value of the task the patient is asked to carry out the less he will be able to respond. The teaching of Jackson remained without fruit, first, owing to the profundity of its thought; and secondly, owing to the rise of a succession of brilliant dogmatists, led by Bastian, who propounded achemes and diagrams which gave apparently simple explanations of the phenomena. Recognition of the fact that it was only by twisting of the clinical findings that a case could be fitted into any particular scheme resulted in the publication in 1906 by Pierre Marie of his "Revision of the Question of Aphasia." He maintains tbat the aphasia of Broca was a combination of two distinct troubles, anarthria and aphasia, the former being simply inability or difficulty of articulating words without any defect of internal language, the latter corresponding to the "sensory aphasia" of Wernicke, which term should disappear. There followed the great discussion at Paris in June, 1908, which resolved itself mainly into a verbal battle without any real advance. Having closely studied the writings of Jackson, devised a new method of examination, and applied it to a large number of cases, Head propounds a new classification of these "disorders of symbolic thinking and expression," claiming that the observed facts show disturbance of these higher psychological processes and not of particular physiological functions subserving speech. The diagram makers worked on the assumption that we think in words; Jackson and Head maintain that we think in symbols, ranging from simple matching of two sensory patterns to recognition of abstract propositions. - The number closes with a discussion on Aphasia at the Royal Society of Medicine, in which Dr. J. Collier, Sir James Purves Stewart, Dr. Kinnier Wilson, Mr. Herbert Parsons, Dr. Stanley Barnes, and Dr. Head took part.

Is the Military Surgeon for March Lieutenant-Colonel E. E. Irons, Medical Corps, U.S. Army, discusses in a long and valuable paper the pneumonia which, in the last four months of 1918, followed influenza in the camps in the United States. There were more than 365,000 cases of influenza, and some 20,000 deaths. The case mortality of this pneumonia varied between 6 and 11 per cent. In one camp of 35,000 men the mortality during seven weeks was 3 per cent. of the total force. Influenza, also the complicating pneumonia, attacked more heavily the recruits and men from country districts. To struggle against the disease, or to attempt to carry on in spite of it, was dangerous. Hence non-commissioned officers and regular army nurses had a high mortality. On the other hand, there was little pneumonia amongst patients already in hospital who were attacked with influenza. The essential pathological condition produced in the lung by influenza was an enormous cedema with little consolida tion, and many hæmorrhages due to necrosis of the interalveolar capillaries. No bacillus was at this stage recognised, but influenza lowered resistance and gave opportunity to the infections already in the naso-pharynx to develop, and so set up pneumonia. The microbic character of the pneumonia varied from camp to camp and period to period. Colonel Irons describes the morbid anatomy of the pneumonia, differing as it was due to pneumococcus, streptococcus, Pfeiffer, or staphylococcus. Tuberculosis as a sequel was rare. The best treatment proved to be early rest in bed, good nursing, and the prevention of complicating infection. No routine treatment could be advised. Convalescence was prolonged. Convalescents got double rations, and being still hungry were given bacon and beans additional. They were put through graduated exercises, beginning with a short five-minute walk twice a day, and went on to games and hard work. Care was taken that they were not discharged too soon, for their resistant powers had been severely taxed. A paper by Captain Iry A. Pelzman discusses the high venereal rate of the U.S. Army in China. Of 100 men, 89 risk infection and 23 get it. Why? Prophylactic treatment in Tientsin is a long way from the centre of the town, and it is therefore proposed that tolerated houses be established on the U.S. Concession. The women would be kept clean, and prophylactic measures would be close at hand for the men, and there would be a lower venereal rate.-There is a most entertaining article Doctors in Uniform, by Dr. H. W. Dana, of Boston, Massachusetts, giving account of the experiences and training of civil practitioners called up for the war. He tells of the difficulty there was in getting special chances of leave and the excuses that were not accepted. "Grandmothers" funerals did not go," he says. One doctor who arrived with a black umbrella was induced to travel three miles to exchange it with a quartermaster for another in a regulation khaki shade. The drill was beneficial, the discipline was improving, and the post-graduate special courses were wonderful. One candidate for a commission asked to mention intestinal parasites could only mention twotyphoid and paratyphoid. Dr. Dana is certain that no man who went to the Medical Officers' Training Camp man who went to the Medical Offcers Training Camp professionally. Many officers have apparently been writing at Christmas from the United States to Sir John Goodwin the Director-General of the Army Medical Service, and he has sent them a letter of thanks addressed to SurgeonGeneral M. W. Ireland, at Washington, recalling how generously their service supported us in 1917, and how much the support and help of those 1000 medical officers and 700 nurses meant to our armies.

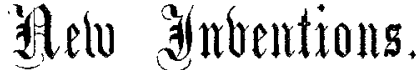

\section{A URETHRAL AND SINUS DRAINAGE BOUGIE.}

BEING interested in the treatment of gonorrhoea as practised by the Australian medical officers at Codford Camp I have had made for me a drainage bougie with a view of improving the technique. It is simply a tubular mesh of white silk closed at one end (see figure) through the centre of which runs a thin vegetable fibre. Its length is about $t$ inches, the central core being several inches longer and its flexibility allows easy insertion into the urethra or sinus. Its mode of application is painless. The urethra being cleared by urination a sterilised urethroscope tube with the pilot is inserted; the pilot is then withdrawn and the duainage bougie saturated with any desired solution, such as permanganate of potash, protargol, acriflavine, and so forth, is introduced. The urethroscopic

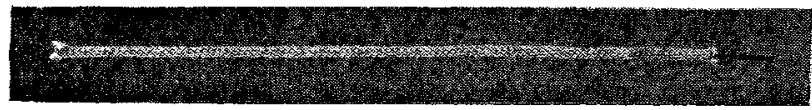

tube is now withdrawn leaving the drain in situ. Finally, the central core is pulled out, leaving the drainage-tube in the urethra. The drain gives no discomfort and is well tolerated. The advantage of this form of treatment is that all parts of the mucous lining come into contact with the antiseptic employen and there is no risk, as in syringing, of driving the pus into the posterior urethra, which I believe is a common cause of cystitis, prostatitis, and orchitis. I can conceive no more rational treatment of gonorrhoea thad by the employment of this method. I have treates several cases with excellent results, but the number is too small for statistical purposes. I am having a glas, endoscopic tube made for introducing the drainage-tube which could be used by the patient. This method might also be employed for the drainage of small sinuses, fistula, and for other purposes.

The silk bougies have been made for me by the Aurorascope Co., Ltd., Fulwood House, Fulwood-place, Holborn, W.C.

$$
\text { Berkeley-street, W. M.D., M.R.C.S., L.R.C.P.Lond. }
$$

\section{A TUBE FOR BLADDER DRAINAGE.}

IT has always appeared to me that the methods of bladder drainage commonly employed after cystotomy are a reproach to surgery, and that if the care exercised in the modern theatre was extended to the obtaining of a water-tight and aseptic bladder the results of vesical surgery would be much improved. The usual method of placing a stout tube in the bladdor and sewing the incision around it permits the bladder to retract into the pelvis, and invariably allows leakage around the sides of the tube, and contamination of the prevesical space. In some cases the tube presses painfully on the trigone and tenesmus results. In a few, I imagine, the bladder withdraws itself over the end of the tube; in any case prevesical infection is common and ammoniacal decomposition and deposit of phosphates occur in a large proportion of cases. 


\section{A French Method.}

In search for improved methods I came first on a procedure used by French surgeons. A de Pezzer catheter of large size (say, 32 French) is introduced into the upper angle of the wound and the remainder carefully sewn up so as to allow of no leakage. A purse-string suture is placed around the tube to keep the bladder wall in constant apposition with it. The expanded end of the tube is drawn up so as to sit firmly against the mucous membrane around the margin of the bladder incision. Two fine catgut sutures, one above and one below the tube, hold the bladder up against the rectus muscle. In this way I found that I got a perfectly water-tight joint, not a drop of urine escaping into the wound, and that union per primam was invariable. Yet the method seemed to me to present three grave defects. In the first place, drainage was good enough in uncomplicated cases; yet wherever post-operative bleeding might occur, as for instance after prostatectomy, I could foresee grave risk of a clot obstructing the small eyes of the catheter, and a dangerous clot-retention occurring. In the second place, irrigation could only be performed by means of the tedious and meddlesome method of syphonage, which is intermittent, inefficient, and disturbs the patient, besides alternately distending and collapsing the bladder and so tending to produce leakage. Thirdly, it is the topmost point of the bladder which is drained.

\section{Modification of the de Pezzer Method.}

To obviate these three faults I have had a tube prepared for me by Messrs. Allen and Hanburys (Fig. 1). It is a de Pezzer catheter, in which the end has been altered into a flange as shown in Fig. 1. This flange is curved slightly backwards towards the tube, so that when drawn up into position in the bladder wound there is a degree of elastic tension which makes a secure joint. The size of the exit provided by this

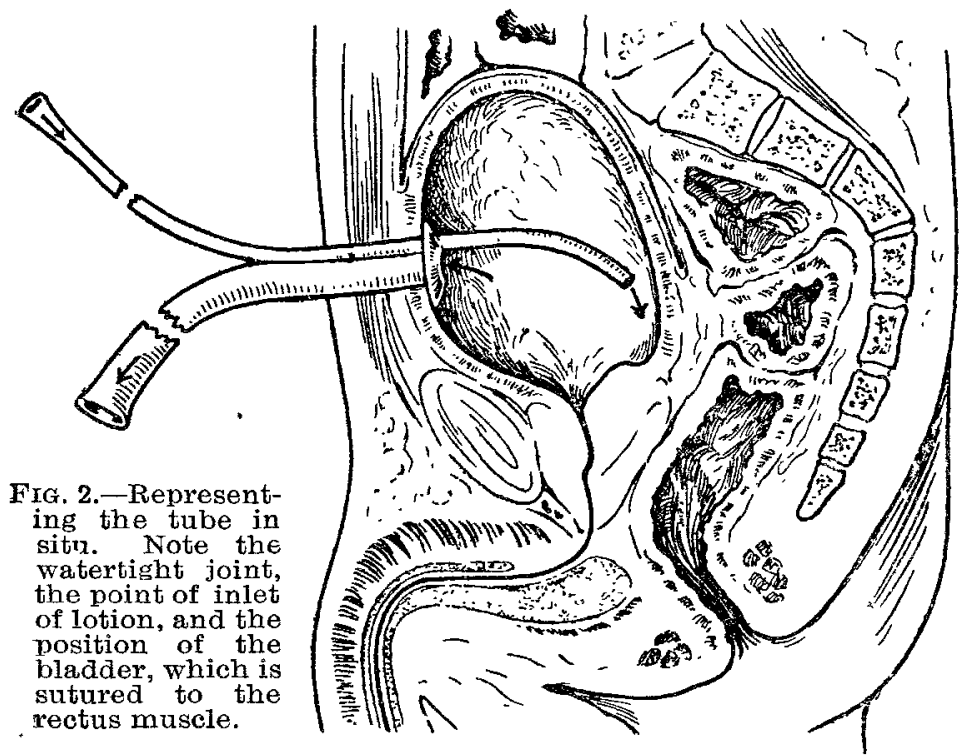

tube is sufficient to preclude any likelihood of a clot obstructing it. Vulcanised against the side of the larger tube is a smaller one, which passes through the flange; when in position, this projects into the bladder base, its external end is connected to a reservoir of lotion, through which constant irrigation of the bladder is effected, the flow leading into the bladder at its lowest point. There is thus a constant flow of fuid through the bladder, and no stagnation can occur in the bladder sump.

Details of Method.

By this method I have been successful in obtaining a perfectly dry wound in practically every case, the first dressing being allowed to remain in position until the tube is removed. I allow the tube to stay in for upwards of a week, considering that it is a valuable asset to have healing well advanced and the prevesical space firmly shut off before taking it ont; after that the urine in drained into a Hamilton Irving suprapubic dish. Simple traction serves for the withdrawal of the tube, the intravesical flange crumpling up and passing through the wound without any difficulty. I do not know how long the bladder remains adherent to the abdominal wall, but certainly not for any long period. In all cases I have found that it functions perfectly when the suprapubic wound is healed. I have also proved that the upper wall of the bladder descends properly by observing if as it empties itself through an irrigating cystoscope.

In order to make sure that the bladder is not held in position for too long my stay sutures are of medium or fine ten-day catgut. Another, and perhaps a better, method is to use two sutures of silkworm-gut, which are passed right through the abdominal wall and support the bladder, pretty much in the same way as tension sutures are used to support the sheath of the rectus after a laparotomy; these are removed when the bladder-tube is withdrawn.

The tube should be placed in the upper angle of the bladder wound and should emerge about the middle of the skin incision. If it is placed too near the pubes there is a

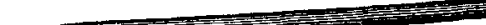

\section{SCALE $\frac{1}{4}$}

age and irrigation tube. Total length 16 inches, diameter nearl

danger of adhesion occurring between the bladder wall and the os pubis, and formation of a fistula. An excellent reservoir for lotion is a thermos flask fitted with a Souttar's syphon, and suspended above the patient's bed. A flask of two quarts capacity can be obtained. The speed of the flow can be regulated by a cock on the syphon. It is a good plan to run the fluid alternately fast and slow, as when it is running fast it creates a disturbance in the bladder sump and cleanses it efficiently.

As regards the lotion to be used, I think that boric acid (sat. sol.) or oxy-cyanide of mercury (1-6000) is the most generally useful, but medication of the bladder can be applied with ease to suit varving circumstances; for instance, in the case of hæmorrhage, adrenalin or silver nitrate can be used; in the case of pain, phenacetin, novocaine, or stovain. It is generally well to keep the bladder fairly acid, and the addition of some acid sodium phosphate to the lotion can be recommended.

The temperature of the lotion in the thermos must be higher than that at which it is desired it should be when it reaches the bladder, as about $4^{\circ}$ to $8^{\circ} \mathrm{F}$. will be lost in passing down the tube according to the speed at which it is running. I find that patients experience comfort from this irrigation, especially if the lotion reaches the bladder at about $100^{\circ} \mathrm{F}$. and when the flow is fairly quick.

I have treated this subject from the point of view of surgical cleanliness and the avoidance of leakage and of phosphatic deposit in the wound; but there is another aspect of the question which is probably of equal importance, and which I consider does not receive the attention which it deserves. A considerable proportion of cystotomy cases, especially among elderly prostatics, are on the verge of uræmia, which the operation accelerates or precipitates, not infrequently with a fatal issue. It seems to me reasonable to believe that a considerable share is played in this mortality by the absorption of toxic urinary bodies from the prevesical space. It is well known that if urine is injected into healthy rabbits a lethal dose is soon reached. How much more shall a dose prove lethal to a patient whose blood urea has already reached the danger zone, when urine is extravasated into the prevesical space-that excellent absorption area-especially when the effects of the operation are superadded? I hope to return to this subject. In the meantime I refer to it in order to emphasise the importance of a dry cystotomy wound.

JAS. B. MACALPINE, F.R.C.S.,

Honorary Surgeon and Surgeon-in-Charge of GenitoUrinary Department, Salford Royal Hospital, \&c.

Literary Intalimance.-Messrs. Kegan Paul and Co. announce the decision to enlarge the scope of The Psychic Research Quarterly and to transform it into a general review of applied and general psychology under the title of Psyche. Education, psycho-analysis, industry, religion, social and personal relationships psychical research \& will come within the scope of the new series, the first number of which will appear on July $15 \mathrm{th}$. 